\title{
Determination of bus drivers' biological age
}

\author{
Deryugin O.V. ${ }^{1 \mathrm{AB}}$, Cheberyachko S.I. ${ }^{2 \mathrm{ACD}}$, Tretyak O.O. ${ }^{1 \mathrm{BCE}}$, Cheberyachko I.M. ${ }^{3 \mathrm{AD}}$ \\ ${ }^{1}$ The Department of Transport Control, State Higher Educational Institution «National Mining University», Ukraine \\ ${ }^{2}$ The Department of Aerology and Labour Protection, State Higher Educational Institution «National Mining \\ University», Ukraine \\ ${ }^{3}$ The Department of Mining Mechanics, State Higher Educational Institution «National Mining University», Ukraine
}

Authors' Contribution: A - Study design; B - Data collection; C - Statistical analysis; D - Manuscript Preparation; E - Funds Collection.

\begin{abstract}
Purpose: It is determined the influence of harmful production factors on determining the nature and rate of aging of bus drivers.

Material: $\quad$ The experiment was attended by 12 drivers aged 28 to 45 years. Work experience - from 5 to 20 years. Hygienic assessment of the main unfavorable production factors (vibration, dust, noise, climatic conditions, etc.) was carried out at the workplaces of drivers of route buses (Ukraine).

Results: It was also determined and compared the biological age of drivers. It has been established that with an increase in the seniority of drivers, their aging rate increases. In the group of drivers with experience less than 10 years (calendar age 35 ), the rate of aging was 4.7 years. With the work experience of drivers of $10-15$ years (calendar age 35 years), the rate of aging was 7.6 years. The average age of biological drivers over calendar drivers is 7 years.

Conclusions: It is confirmed that work under conditions of harmful factors' influence the production environment worsens the health of drivers and reduces the duration of their lives.

Keywords: biological age, harmful production factors, driver, route bus, hygienic requirements.
\end{abstract}

\section{Introduction}

The efficiency and safety of the transport process for the transport of passengers by road directly depends on the psychophysiological state and health of the driver, the requirements of which are regulated by the current legislation. It is well-known that the adverse effects of harmful factors on drivers during transport work (tense and often changing conditions of the transport process for passenger transportation, the responsibility for the safety of passengers in times of shortage, the imperfection of the design of motor vehicles, the influence of harmful substances), leads to the risk of developing occupational diseases and has an impact on the course of common diseases. Among the main risks of occupational diseases, one can distinguish the following - diseases of the circulatory system, diseases associated with fatigue, fatigue and depression (Fig. 1 [1]).

One of the main modern problems in road transport is the improvement of the quality of passenger transportation. This essentially depends on the rational use of vehicles, the full safety of the participants in the transport process, the culture of service [2]. Of course, the organization of passenger transportation must take into account the driver's functional state and his ability to work, which largely depends on the sanitary and hygienic conditions of work [3]. Also, the safety of passenger traffic is influenced by the psychophysiological state of the driver. It is believed that noise, vibration, elevated air temperature, nervous-emotional stress (Fig. 2) affects it [Fig. 2] [4, 5].

A lot of attention is paid to the study of hygienic

() Deryugin O.V., Cheberyachko S.I., Tretyak O.O.,

Cheberyachko I.M., 2018

doi:10.15561/18189172.2018.0203 conditions of drivers. On their basis, appropriate standards are developed to ensure the proper working capacity of drivers. However, the problem of maintaining occupational health and creating safe working conditions for drivers remains relevant for all countries of the world $[6,7]$. This is due to the growth of psychological stresses, increased traffic flow, increased input information for decision-making, increased liability for the safety of the type of traffic, the complexity of the routes.

It should be noted that in Ukraine the regulated requirements for organization of work and rest of drivers have become more frequent. Significantly weakened by the control of the structures of state supervision of the state of drivers' health. This has led to an increase in fatal accidents at the workplace during the transport process and the occurrence of occupational diseases.

At one time, a significant number of publications on this issue were published by domestic and foreign scholars. In particular, Davidich Iu.O. et al [8] were considered the issues of ergonomic provision of the transport process in order to minimize its impact on the workability of drivers. The author has found the possibility to link the change in the physiological state of drivers with the length of the route, its complexity, the power of the car and other parameters. However, little attention has been paid to the impact of sanitary conditions on driver's state of health. This same drawback is manifested in other works [9]. The author considered the problem of optimization of the transport system. Similar data are shown in the work of Lobashov O.O. et al [10]. The author studied the problem of driver's ability to work, his ability to perform physical and mental work, keeping a given pace, the ability not to get tired while driving and overcome fatigue. This direction is also reflected in the scientific 


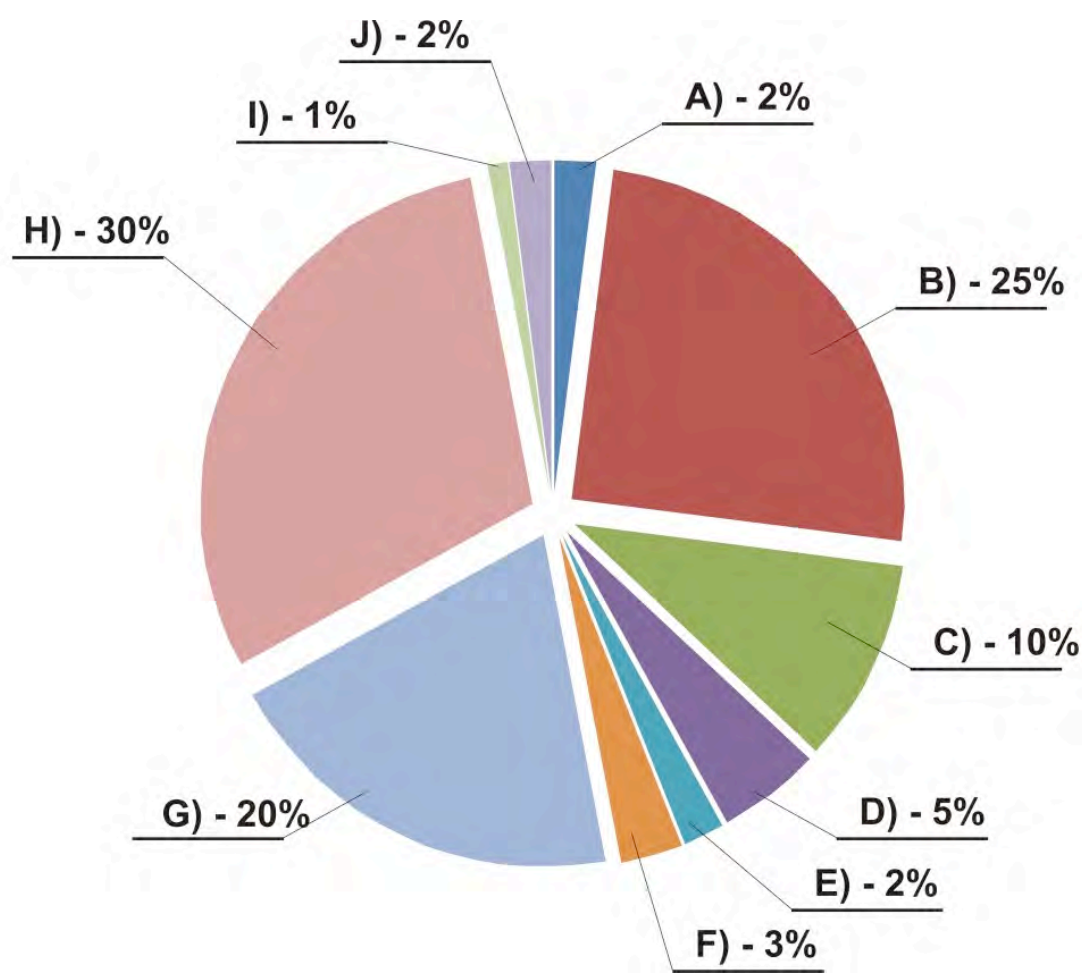

Fig. 1. The structure of the risks of drivers' occupational morbidity, who carry out passenger transport by bus [1]: A) - Diseases of the nervous system; B) - Diseases of the circulatory system; C) - Diseases of the respiratory system; D) - Diseases of the digestive system; E) - Diseases of the genitourinary system; F) - Diseases of the endocrine system; G) - Reduced efficiency caused by stressful situations; H) - Symptoms of fatigue, fatigue and depression; I) - New formation; J) - Other diseases.

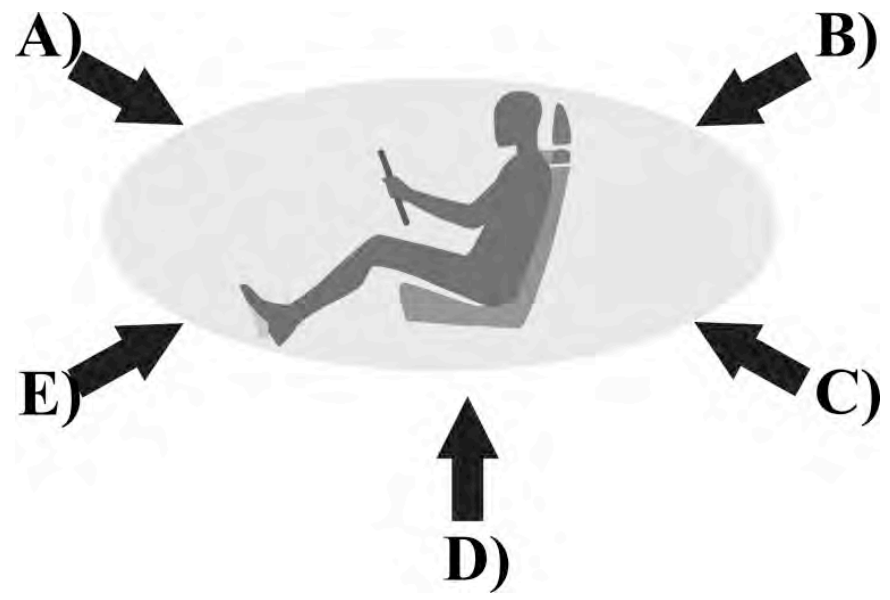

Fig. 2. Harmful production factors of the environment that have an impact on the health of drivers of route buses [4, 5]: A) - Noise; B) - Nervous-emotional stress; C) - Harmful substances; D) - Unfavorable microclimate of the working environment; E) - Vibration.

works of Cybulski M. and Yang J. They substantiate the relationship between the type of personality and its ability to carry the load with the behavior on the road in order to reduce the accident rate $[11,12]$. Other results were shown in the work of Liebiedieva T.L. et al [13]. The authors established the relationship between the discrepancy of regulatory requirements of the duration of the management period and chronic fatigue and increased nervous-emotional tension. All this causes changes in the vegetative nervous system of drivers and increases the risk of developing cardiovascular diseases and diseases of the digestive system. However, an existing connection is not established: between working conditions and the risk of developing diseases; between the influence of harmful factors on reducing the driver's life expectancy [14]. Therefore, an urgent task is to assess the impact of harmful production factors and working conditions on the nature and rate of aging of bus drivers. At the heart of this is the definition of drivers' the biological age (BA).

Recently, more and more attention is paid to the criterion of health assessment in the form of biological age. Biological age characterizes the functional state of the 
organism and reflects the overall "viability" of the person. To do this, use two types of objective and subjective evaluation indicators. The first group includes the functioning of reserve capabilities of the cardiovascular and respiratory systems with the locomotor apparatus. It takes into account the age-old features of people. The second is the subjective evaluation of health according to the questionnaire. This assessment reflects, to some extent, the characteristics of the central nervous system (CNS) [15-18].

Hypothesis. It is assumed that work under conditions of the production environment harmful factors' influence worsens the health of drivers of route buses and leads to the development of occupational diseases and to shorten their life expectancy.

The purpose of the work is to determine the influence of harmful production factors and working conditions on the determination of the nature and aging of bus drivers on the basis of determining their biological age.

\section{Materials and methods.}

Participants. The hygienic estimation of the influence of the main unfavorable production factors (vibration, dust, noise, climatic conditions) was carried out at the workplaces of the drivers of the route buses of the brands Mercedes Benz Sprinter 411, Ruta 23 (Ukraine), Bogdan A20111 (Ukraine). The experiment was attended by 12 drivers aged 28 to 45 with work experience from 5 to 20 years.

Organization of research. Measurement of noise load at the driver's work place was carried out at a speed of $45-60 \mathrm{~km} / \mathrm{h}$. From the indicated speeds, they chose the smallest. The measurements were carried out at five values of constant velocities (with a rounding value of up to $5 \mathrm{~km} / \mathrm{h}$ ): the smallest indicator, the largest indicator and the intermediate metric. At each point of the microphone position of the Octave-101 device (www.zapadpribor. com), three measurements of the noise level value were performed. According to the measurements, the arithmetic mean values, rounded to the integer, were taken. Repeat measurement was performed if the difference between the highest and lowest values of noise levels at each point exceeded $2 \mathrm{~dB}$ (decibels).

Measurements of the parameters of the temperature environment of the working space of the driver were carried out using the thermometer "TENSOR-41" (http://www.tenzor.ua) of the anemometer "TESTO 405V1" (http://trade-control.com.ua) and the aspirational psychrometer "M-34" (http://arsmt.com.ua) and the "MX-2" pyrometer (http://www.izmerimvse.ua). The research was conducted under the following conditions: air temperature in the shade $-+32 \ldots+34{ }^{\circ} \mathrm{C}$, the bus was moving towards the south (deviation from the direction $+15^{0} \ldots 20^{\circ}$ ), the speed is $80 \ldots 90 \mathrm{~km} / \mathrm{h}$. Time to measure temperatures: at the beginning of the change at about $6^{00}$ in the morning, from $12^{00}$ to $13^{00}$ (in the afternoon break) and in the evening at $20^{\circ}$. The temperatures were repeatedly measured in the following zones: driver's head, chest, stomach-thigh, legs-legs. The research was carried out as follows. We have taken into account that the driver and passenger seats are placed symmetrically. Therefore, the climate conditions for the driver and passenger are the same. Therefore, the thermometers were installed at the passenger seat. Measurements were carried out in each zone three times (repeat after 5 minutes).

Concentration of harmful substances in the driver's working space is carried out with the help of the gas analyzer "GC" (http://granat-e.ru), complete with indicator tubes for monitoring: ammonia, benzene, gasoline, xylene, carbon monoxide, toluene, chlorine, nitrogen oxides, hydrogen sulfide, ethyl ether, hydrocarbons (certified in Ukraine). The total dust concentration in the air was determined using the aspirator AERA (http://standart-m. com.ua), which provided (with an air flow of 20 liters $/ \mathrm{min}$.) Sampling in the driver's breathing zone. The analytical filters "AFA-10" were used, which were then weighed on the analytical scales "VLO-200" (http://gosmetr.ru). Sampling time was recorded using the stopwatch "SOPpr2a-2-010" (https://www.zlat-zchz.com/).

Measurement of the vibration load at the driver's workplace was carried out using the digital contact vibrometer "AR63A (GM63A)" (https://mpr-kip. com). Measurement of the level of vibration load in the workplace of the driver of the respective stamps of route buses was carried out under the following conditions: when moving the bus with constant speed; at carrying out transport work on passenger transportation; on a stationary route bus during drivers' places of rest. The study of the vibration of the gearbox was carried out while driving the route bus on the second gear on an equal area of asphalt highway: the rotational speed of the crankshaft 1200-1300 rpm.

To evaluate the functional state of man was used the following technique: the tone meter "Nissei DS1902" (https://http://pribory-si.ru) and "Omron M10IT" (https://http://pribory-si.ru), infrared contactless thermometer "Maniquick MQ-160" (http://www. maniquick.com.ua/), medical scales "BM-150" (http:// gosmetr.ru). Subjective Health Assessment (SHA) conducted using a questionnaire, which included 27 questions (Table 1).

The first 26 questions include "yes" or 'no' answers. The last one - "good", "satisfactory", "bad", "very bad". The number of negative responses is calculated on the first 26 questions and 1 is added if the last question is "bad" or "very bad". The total number of points gives a quantitative self-esteem of health (index of self-esteem of health) with "ideal" and 27 with "very bad" state of health.

The informativeness of this indicator is evidenced by the presence of a correlation between the level of SHA and many objective indicators of the body's condition (blood pressure, vital capacity of the lungs, hearing impairment, body weight). The SHA index also interconnected psychometric tests that reflect cognitive functions the brain.

Biological age (biological age - BA) was determined by the formula [15-18]: 
Table 1. Questionnaire for self-assessment of health [13]

\begin{tabular}{|c|c|}
\hline $\mathbf{N}$ & Questions \\
\hline 1. & Are you having headaches? \\
\hline 2. & Can you say that you easily wake up from any noise? \\
\hline 3. & Do you have a pain around the heart? \\
\hline 4. & Do you think that your eyesight has worsened? \\
\hline 5. & Do you think that your hearing has worsened? \\
\hline 6. & Are you trying to use only boiled water? \\
\hline 7. & Do you give way to a city transport? \\
\hline 8. & Do you bother with joint pain? \\
\hline 9. & Does your mood change the weather? \\
\hline 10. & Are there any cases that you are losing sleep through excitement? \\
\hline 11. & Does bothering you around the liver? \\
\hline 12. & Do you have dizziness? \\
\hline 13. & Is it harder for you to focus than in past years? \\
\hline 14. & Are you worried about memory impairment? \\
\hline 15. & Do you feel in different parts of the body of tingling? \\
\hline 16. & Are you bored in your ears? \\
\hline 17. & Do you keep one of the following drugs validol, nitroglycerin, heart drops in your home medicine kit? \\
\hline 18. & Do you have swelling of your legs? \\
\hline 19. & Do you refuse from some dishes? \\
\hline 20. & Do you have shortness of breath when you are on the go? \\
\hline 21. & Does bothering you with lumbar pain? \\
\hline 22. & Do you use any mineral water for medical purposes? \\
\hline 23. & Can you say that you began to cry easily? \\
\hline 24. & Are you on the beach? \\
\hline 25. & Do you think that you now have the same working capacity as before? \\
\hline 26. & Are there such periods when you feel joyfully excited, happy? \\
\hline 27. & How do you rate your health? \\
\hline
\end{tabular}

$$
\begin{aligned}
\mathrm{BA}=26,985 & +0,215 \times \mathrm{APS}-0,149 \times \mathrm{DBADB}-0,151 \\
& \times \mathrm{SBLL}+0,723 \times \mathrm{SHA}
\end{aligned}
$$

where APS - arterial pressure systolic; DBADB duration of breath holding after deep breathing; SBLL static balancing on the left leg; SHA is a subjective health assessment (shown in Table 1).

Formula (1) allows you to evaluate the BA of each of the surveyed drivers. In order to determine the degree of aging relative to the driver's calendar year $(\mathrm{HY})$, an individual BA was matched to the proper BA (PBA). PBA characterizes the average population standard of the rate of aging.

The BA-PBA index shows how many years of probable BA of an individual ia more or less than the average age of their peers. If the degree of aging is less, then $\mathrm{BA}-\mathrm{PBA}<0$. If the degree of aging is bigger, then $\mathrm{BA}-\mathrm{PBA}>0$. If the degree of aging is the same, then $\mathrm{BA}-\mathrm{PBA}=0$.

Indicators of the functional state of the body (arterial pressure, respiratory depression, static balancing and selfesteem index, weight) were determined at the beginning of the work shift. This procedure is mandatory during a medical review of drivers before the run. Changes in blood pressure were controlled at lunch breaks and after the run. The control of other indicators took place once a month for six months (from March to September 2017).

Statistical analysis. Material processing was carried out using the standard Microsoft Office program Excel 2010. The data obtained had a normal probability distribution law and Student's parametric criteria were used to analyze them. The number of observations was sufficient to obtain unmatched estimates of the first two points: the arithmetic mean (M) and the mean square deviation $(\delta)$. In order to compare the mean values of the quantitative indices in the normal distribution was used Student's criterion. The significance level $\mathrm{p}<0,05$ with reliability of $95 \%$ was considered reliable.

\section{Results}

According to the sanitary-hygienic characteristics of drivers' working conditions, the schedule of work is approved - six-day working week in two changes. In both changes, a regulated technological break for a lunch duration of 30 to 40 minutes is provided. However, observance of the schedule of route buses' drivers is complicated due to fluctuations in passenger traffic, changes in traffic intensity, weather conditions. Also, the participation of drivers in the maintenance and ongoing repair of route buses. This increases the duration of the working day. 
As a result of the sanitary and hygienic investigations of working conditions at the workplaces of drivers, the values of the harmful factors acting on them during movement were determined (Table 2).

It was established that the maximum exceedance of the permissible norms in the cabins of route passenger buses has temperature indices. Their significance since the sixth hour of the drivers (at 10.00-11.00 in the morning) was $43-48^{\circ} \mathrm{C}$. The given data testify that drivers during the warm period of the year (from June to September) work in conditions of elevated temperatures. This is facilitated by external meteorological conditions, the weakness of air conditioning systems in shuttle bus cabins, flows of additional heat from the engine running and solar radiation and from the cabin. The parameters of the microclimate in the cold and transition period of the year also differ from the permissible indicators (fixed from 8 to $21^{\circ} \mathrm{C}$ ). This indicates the inefficiency of ventilation and heating systems.

According to the Hygienic Classification of Labor, the parameters of the microclimate should be classified as harmful 3.2-3.4. Let's also note the impact of labor intensity. Such work is conditioned by the need for continuous monitoring of the road for more than 5-6 hours per shift and a certain nervous-emotional load (responsibility for the safety of passenger transportation). Microclimate is the most adverse factor in all route buses (Fig. 3). Work in such conditions leads to the tension of the body's thermoregulatory functions, which causes an increase in stress on the cardiovascular system. Calculate the average body temperature according to the formula [19]:

$$
\mathrm{t}_{\mathrm{tl}}=\mathrm{K} \times \mathrm{t}_{\mathrm{p}}+(1-\mathrm{K}) \times \mathrm{t}_{\mathrm{sh}}
$$

where $t_{p}$ is the temperature of the "core" of the body (entotic, in the original modification), ${ }^{0} \mathrm{C} ; \mathrm{t}_{\mathrm{sh}}$ - average weighted skin temperature, ${ }^{\circ} \mathrm{C}$; $\mathrm{K}$ - mixing factor.

The average weighted skin temperature $\left(\mathrm{t}_{\mathrm{sh}}\right)$, we determine by five points (measurements will be made at five different points of the human body) [9]:

$\mathrm{t}_{\mathrm{sh}}=0,7 \times \mathrm{t}_{1}+0,5 \times \mathrm{t}_{2}+0,05 \times \mathrm{t}_{3}+0,18 \times \mathrm{t}_{4}+0,2 \times \mathrm{t}_{5}(3)$

where $t_{1}$ - temperature of the surface of the skin of the forehead, ${ }^{0} \mathrm{C} ; \mathrm{t}_{2}$ - temperature of the surface of the breast, ${ }^{0} \mathrm{C} ; \mathrm{t}_{3}$ - temperature of the surface of the body of the brush, ${ }^{0} \mathrm{C} ; \mathrm{t}_{4}$ - temperature of the surface of the upper thigh, ${ }^{0} \mathrm{C}$; $\mathrm{t}_{5}$ - temperature of the surface of the body of the foot, ${ }^{0} \mathrm{C}$.

Another indicator is the assessment of the feeling of sentiment, which was carried out on a seven-point scale: very cold - 1; cool - 2; slightly cool - 3; comfortable - 4; slightly warm - 5; heat - 6; very hot - 7 .

Fig. 4 shows the change in the average body temperature and the thermal sensation of workers during the work shift. From the graph, it is clear that the value of the sense of warmth significantly increased inside and at the end of the change by 0,8-0,9 points in comparison with the beginning of the change, which indicated a significant influence of the thermal environment on the thermal state of the workers $(\mathrm{p}<0,05)$.

In fig. 5 is shown the dependence of the thermal sensation on temperature. With an increase in the temperature of 1 degree above $24^{\circ} \mathrm{C}$, the sensation of heat increases by 0.5 points. At the same time, exceeding the permissible limit of 5 points comes at an air temperature of more than $27^{\circ} \mathrm{C}$ in the cabin. Thus, the upper limit of the negative influence on the driver is an excess of temperature of $27^{\circ} \mathrm{C}$. Possible confirmation of the concluded conclusion is the decrease of fluctuation of diastolic blood pressure (DBP) in winter compared with the summer period of the year (Fig. 6). It is its reduction indicating a significant influence of temperature indices. Increase of the SBP (systolic blood pressure) can take place under the influence of infrared radiation or during physical work. Such data indicate the expressed voltage of functional systems. Lack of change may indicate the ability of a person to tolerate the thermal load. It should be

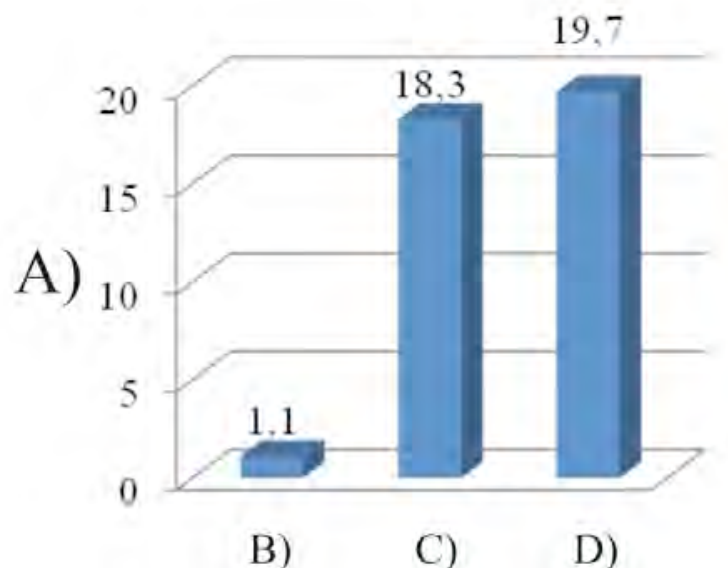

a). in summer

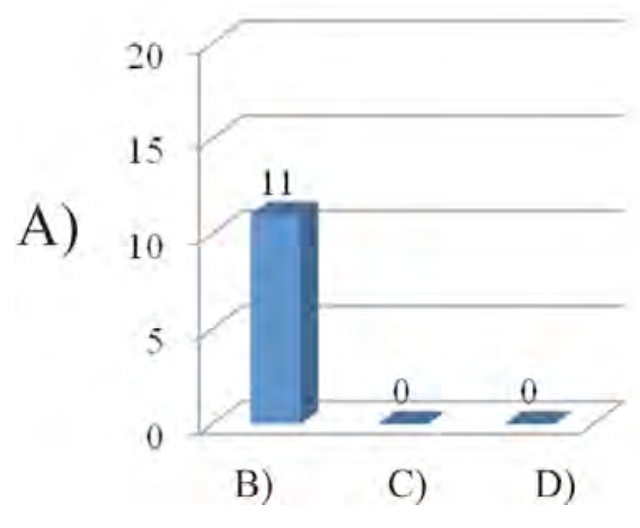

a). in winter

Fig. 3. Exceeding the temperature sensor in the air of the cab passenger route buses during the change: $A$ ) - Temperature, ${ }^{\circ}$; ; B) - Beginning; C) - Middle; D) - End. 

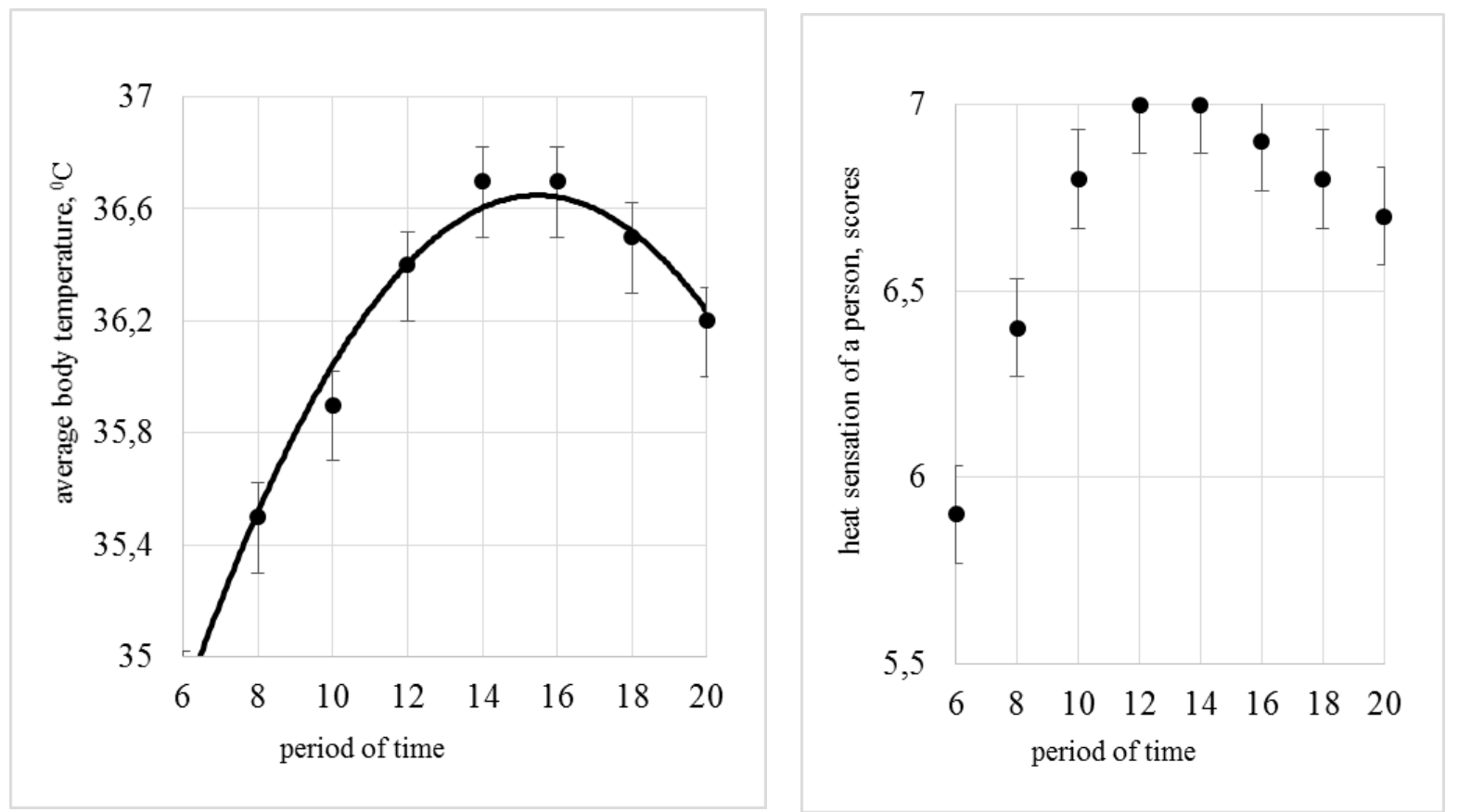

Fig. 4. Change in average body temperature and heat sensation during the day in the driver's cab of route bus in summer.

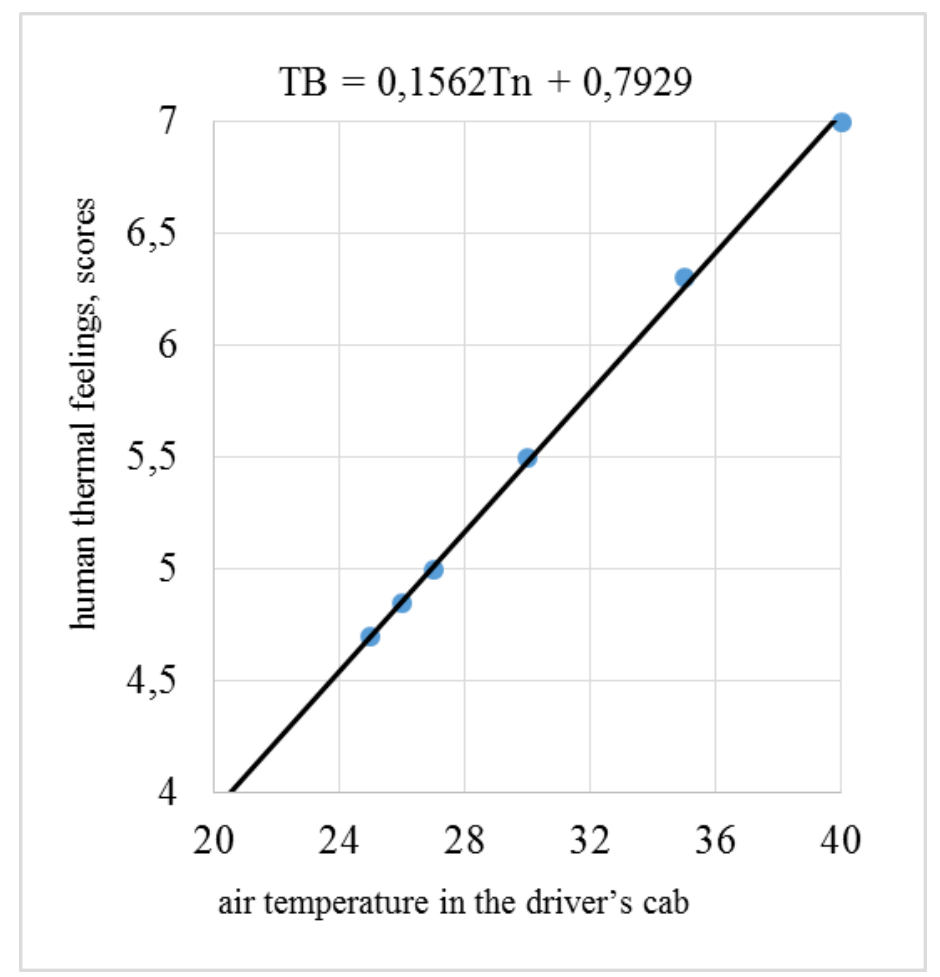

Fig. 5. Dependence of the thermal sensation on the temperature of air in the driver's cabin in the summer: TF - human thermal feelings, scores; AT - air temperature in the driver's cab, ${ }^{\circ} \mathrm{C}$.

noted that the increase in the heart rate in a state of rest is fixed at a temperature exceeding $33^{\circ} \mathrm{C}[20,21]$.

The fact that drivers work in adverse climatic conditions is established. This requires further assessment of the degree of aging of drivers. The results of factors influencing the performance of transport work in the summer are given in Table. 3. Data indicate an increase in systolic blood pressure, heart rate, and a decrease in static balancing time. Table 4 shows the indexes of basic physiological tests in drivers.

Analysis of the results shows that with the increase in the length of work of drivers increases their rate of biological aging. So in the group of drivers with work experience less than 10 years and the calendar age of 35,4 years the rate of aging was $-4,7$ years. With an employment record of 5 to 10 years and a calendar age 


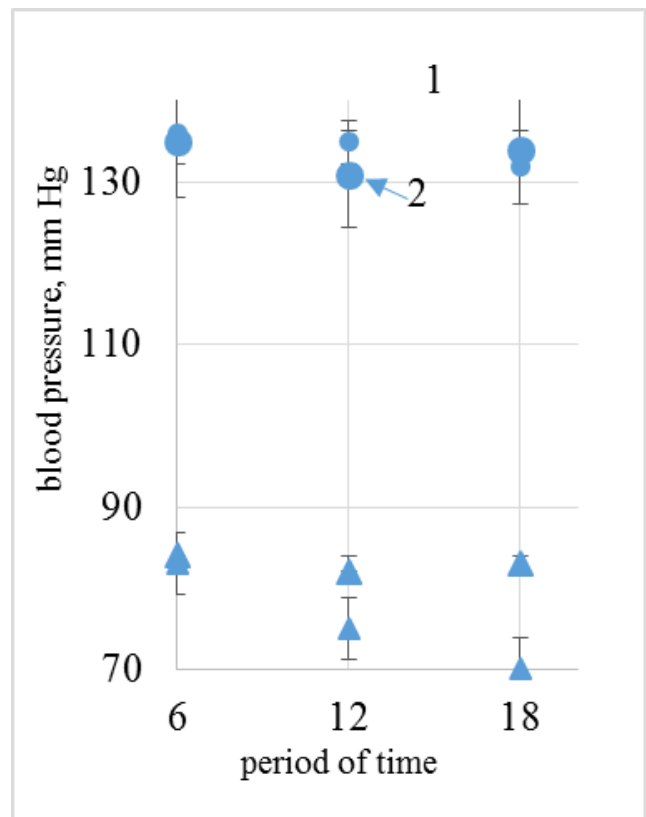

Fig. 6. Fluctuations in systolic ( $\bullet$ ) and dystolic ( $\mathbf{\Delta})$ blood pressure in summer (1) and winter (2)

Table 3. Estimated average values of the indicators of the functional state of drivers at the beginning and at the end of the change

\begin{tabular}{lllll}
\hline Indices & Before change & After change & $\begin{array}{l}\text { t-Student's } \\
\text { criterion }\end{array}$ & Significance level (p) \\
\hline SBP, mm Hg & $136,08 \pm 1,06$ & $139,64 \pm 1,44$ & $-1,9954$ & 0,047 \\
DBP, mm Hg & $81,59 \pm 0,81$ & $71,64 \pm 0,74$ & $-0,9544$ & 0,34 \\
Heart rate, beats per & $72,41 \pm 0,46$ & $81,30 \pm 0,56$ & $-12,2870$ & 0,0001 \\
minute & $26 \pm 3,46$ & $11 \pm 0,46$ & $-3,954$ & 0,412 \\
SB, $\mathrm{S}$ & &
\end{tabular}

Note. SBP - systolic blood pressure; DBP - diastolic blood pressure; SB - static balancing on the left foot, seconds.

Table 4. Indicators of basic physiological tests in drivers

\begin{tabular}{llllllll}
\hline $\begin{array}{l}\text { Seniority, } \\
\text { age }\end{array}$ & $\begin{array}{l}\text { Quantity, } \\
\text { drivers }\end{array}$ & Middle age, age & $\begin{array}{l}\text { SBP, } \\
\mathbf{m m ~ H g}\end{array}$ & BHE, s & SB, s & $\begin{array}{l}\text { SEH, } \\
\text { points }\end{array}$ & BA, years \\
\hline $5-10$ & 4 & $35,4 \pm 0,9$ & $121,4 \pm 2,6$ & $33,9 \pm 3,5$ & $82,1 \pm 1,3$ & $6,4 \pm 0,6$ & $40,1 \pm 1,1$ \\
$10-15$ & 5 & $35,5 \pm 1,4$ & $133,1 \pm 3,2$ & $40,3 \pm 2,1$ & $76,2 \pm 2,5$ & $7,1 \pm 0,7$ & $43,2 \pm 0,9$ \\
more than & 3 & $37,4 \pm 0,7$ & $134,8 \pm 2,5$ & $35,6 \pm 2,3$ & $72,1 \pm 1,8$ & $10,7 \pm 0,5$ & $46,8 \pm 0,9$ \\
15 & & & & &
\end{tabular}

Note. SBP - systolic blood pressure; BHE - breath hold while exhaling, seconds; SB - static balancing on the left foot, seconds; SEH - self-esteem of health, points.

of 35.5 years, this figure was -7.6 years. Thus, drivers of coach buses with different work experience (from 5 to 10 years and more than 10 years) have a different aging rate. This allows us to conclude that the influence of professional activity of drivers on the rate of aging. This is to a certain degree reflects the state of their health.

The excess of the biological age over the calendar average is 7 years. According to available data, the difference between BA and the appropriate biological age is equal to 7 years. It characterizes relatively small premature aging.

\section{Discussion.}

The result can be explained by the fact that drivers' working conditions are characterized by a high degree of neuro-emotional stress. According to indicators (intellectual and emotional load, sensory voltage, load monotony and mode of operation), it can be attributed to the conditions of harmful work of 2 degrees. During the survey, it was found that about $80 \%$ of drivers experience 
physical and emotional fatigue after work. This is due to the fact that drivers work for about 10-12 hours and more in one change. This significantly exceeds the permissible standards that regulate this type of transport work. Such working conditions lead to the development of new or to deepen existing chronic diseases. This accelerates the aging process. These include hypertension, chronic ischemic heart disease and stomach ulcer. It can be traced the direct dependence of premature aging of drivers from the conditions of work [22]. The analysis of the test results of the BA allowed to distinguish from the set of physiological parameters the main factor of the formation of BA: arterial pressure (systolic and diastolic). When analyzing the incapacitated letter, it was found that hypertension among drivers ranks first.

This conclusion is confirmed by works by Giuliev N.U. [23] and Ge Y. [24]. The authors studied the change in the psychological state of the driver in traffic flows of varying intensity. The results of their research indicate that the greatest emotional stress of the driver is observed, if necessary, frequent stops, ahead of vehicles. Also, there is a difference in speed in the ride cycle, a driver's execution of a large number of maneuvers.

To the adverse factors of the driver's health on the bus in the cabin is: noise, vibration, elevated air temperature, the presence of pollination and gas pollution of the workplace. In another study [25], it was found that excessive noise levels reach up to $7.7 \mathrm{dBa}$, vibrational to
$-20 \mathrm{~dB}$. This contributes to reducing the hearing of drivers [26]. Similar data are also determined when calculating the dynamics of vehicles [27]. Indicators of temperature in the summer exceed by $15-20^{\circ} \mathrm{C}$. Their joint action leads to reduced efficiency and reduced adaptive capacity of the person. The result is the premature aging of a person.

Consequently, in order to increase the life expectancy of drivers, it is necessary to reduce the harmful effects of negative factors. It is recommended to view the modes of work and rest. It should be ensured their work is not more than 8 hours with obligatory breaks for rest after each flight made at least 45 minutes.

\section{Conclusions}

It is confirmed that work under conditions of production environment harmful factors' influence (especially in conditions of elevated temperatures) worsens the health of drivers and reduces their life expectancy. There is also a decrease in reserve capacity of the body caused by accelerated wear and tear of the cardiovascular system. The discrepancy between the biological age and the calendar age is influenced by a high degree of nervousemotional stress. This factor is also reflected in the cardiovascular system of the body.

\section{Conflict of interest.}

The authors state that there is no conflict of interest.

\section{References}

1. Sukhova IaM. Assessment of occupational health risks of drivers of specialized vehicles. Cand. Diss. Sankt Petersburg; 2009. (in Russian)

2. Davidich NV. Modeling of quality indicators of urban passenger transport. Visnik Skhidnoukrains'kogo nacional'nogo universitetu im. V. Dalia, 2016;1(225):69-73. (in Ukrainian)

3. Dadonova KV, Bokatova MI. Analysis of working conditions of drivers of vehicles. Komunal'ne gospodarstvo mist, 2015; 120(1):234 - 235. (in Ukrainian)

4. Zakharov SV, Legusova DN. Analysis of working conditions of drivers of motor transport. Bezopasnost' $v$ tekhnosfere, 2012;3:46-48. (in Russian)

5. Klimenko TV. Estimation of working conditions of drivers of passenger motor transport on the noise figure in the workplace. Mezhdunarodnyj studencheskij nauchnyj vestnik, 2017;4(5):34-40. (in Russian)

6. Karakushikova AS, Toguzbaeva KK, Niiazbekova LS, Sejduanova LB, Zhunistaev DD, Nurshabekova AB. Hygienic assessment of the contamination of the working environment of drivers of motor vehicles and preventive measures. Vestnik KAZNMU, 2012;2:15-20. (in Russian)

7. Furukawa T. Assessment of adequacy of the multiregression method to estimate biological age. Practical Handbook of Human, Biological age Determination. Bocca Ration: CRC Press; 1994.

8. Davidich IuO, Kush IeI, Ponkratov DP. Ergonomic provision of transport processes. Kharkiv; 2011. (in Ukrainian)

9. Ershova AN. Optimization of the city's transport system by parking system. Tekhnika $i$ tekhnologiia transporta, 2017;1(2):45-50. (in Russian)
10.Lobashov OO, Burko DL, Prasolenko OV. Regularities of the functioning of the ergonomic system: "driver - car - subject of work (travel of the driver) - environment" in the city. Kharkiv: Lider; 2016. (in Ukrainian)

11.Cybulski M, Strzelecki W, Grzymisławska-Cybulska M, Głowacka MD, Mojs E. Determinants of personality and risky road behaviors at work in drivers of medical transport vehicles in the Wielkopolska. Med. Pr., 2014;65(4): 485-496.

12. Yang J, Du F, Qu W, Gong Z, Sun X. Effects of personality on risky driving behavior and accident involvement for Chinese drivers. Traffic Inj. Prev. 2013;14(6): 565-571.

13.Liebiedieva TL, Gurov SV, Petrov VA, Chornij IuO. Study of the health status of taxi drivers according to the results of the questionnaire survey. Aktual'nye problemy transportnoj mediciny, 2016;2(44):67-73. (in Ukrainian)

14.El'garov AA, Kalmykova MA, El'garov MA. Motor transport medicine - experience, problems, prospects, the right to recognition. Medicina truda i promyshlennaia ekologiia, 2014;5:3-7. (in Russian)

15.Kozina Z, Iermakov S, Bartík P, Yermakova T, Michal J. Influence of self-regulation psychological and physical means on aged people's functional state. Journal of Human Sport and Exercise, 2018;13. doi:10.14198/jhse.2018.131.10

16.Demec'ka OV, Gorban' LM, Kucheruk TK, Movch VO. Biological age and some indicators of homeostasis in workers of the main occupations of ferroalloys production. Dovkillia ta zdorov'ia, 2002;3:34-37. (in Ukrainian)

17.Kashuba NA. On methodological approaches to assessing the biological age of a person. Gigiena truda, 2003; 34: 813825. (in Russian)

18.Abramovich SG, Mikhalevich IM. The biological age of a person, the cardiovascular system and the rate of aging. Klinicheskaia medicina, 2001;5:3-32. (in Russian) 
19.Jacklitsch B, Williams WJ, Musolin K, Coca A, Kim J-H, Turner N. Cincinnati NIOSH criteria for a recommended standard: occupational exposure to heat and hot environments. National Institute for Occupational Safety and Health, DHHS (NIOSH); 2016.

20.Nazarenko VI, Tereshchenko PS, Palijchuk SP, Nikiforuk OI, Chuj TS. Physiological and hygienic assessment of microclimate of modern office premises and adaptive reactions of the body of office workers. Ukrains'kij zhurnal z problem medicini praci, 2014;2:41-47. (in Ukrainian)

21.Bogdanov AV. Improving the microclimate parameters in the cabs of mobile machines. Bezopasnost' zhiznedeiatel'nosti, 2009;5: 8 - 10. (in Russian)

22.Kerefova ZSh, Zhilova II, El'garov AA. Ischemic heart disease in drivers of motor vehicles (frequency, professional performance). Kardiovaskuliarnaia terapiia i profilaktika, 2007;6(7):25-30. (in Russian)
23.Giuliev NU. Features of ergonomics and psychophysiology in the driver's activity. Kharkiv: KNACH; 2012. (in Ukrainian)

24.Ge Y, Qu W, Jiang C. The effect of stress and personality on dangerous driving behavior among Chinese drivers. Accid. Anal. Prev. 2014;73: 34-40.

25.Deryugin OV, Cheberyachko SI. Substantiation of the choice of a truck on the criterion of minimizing the psychophysiological load on the driver. VostochnoEvropejskij zhurnal peredovykh tekhnologij, 2015; 3(75):1522. (in Ukrainian)

26.Lie A, Skogstad M, Johannessen HA. Occupational noise exposure and hearing: a systematic review. Int. Arch. Occup. Environ. Health. 2016;89(3): 351-372.

27.Ziborov KA, Protsiv VV, Fedoriachenko SA. On formation of kinematical and dynamical parameters of output elements of the mine vehicles in transient motion. Scientific Bulletin of National Mining University, 2013;p 4: 65-70.

\section{Information about the authors:}

Deryugin O.V.; http://orcid.org/ 0000-0002-2456-7664; oleg.kot@meta.ua; The Department of Transport Control, National Mining University; 19, D. Yavornyts'kogo av., 49005, Dnipro, Ukraine.

Cheberyachko S.I. (Corresponding author) ; Doctor of Technical Sciences; http://orcid.org/ 0000-0003-3281-7157; sicheb@ukr.net; The Department of Aerology and Labour Protection, National Mining University; 19, D. Yavornyts'kogo av., 49005, Dnipro, Ukraine.

Tretyak 0.0.; http://orcid.org/ 0000-0002-6991-0235; elena.novikova.ut@ukr.net; The Department of Transport Control, National Mining University; 19, D. Yavornyts'kogo av., 49005, Dnipro, Ukraine.

Cheberyachko I.M.; http://orcid.org/ 0000-0002-6193-5729; cheberiachko.i.m@nmu.one; The Department of Mining Mechanics, National Mining University; 19, D. Yavornyts'kogo av., 49005, Dnipro, Ukraine.

Cite this article as: Deryugin OV, Cheberyachko SI, Tretyak OO, Cheberyachko IM. Determination of bus drivers' biological age. Pedagogics, psychology, medical-biological problems of physical training and sports, 2018;22(2):77-85. doi:10.15561/18189172.2018.0203

The electronic version of this article is the complete one and can be found online at: http://www.sportpedagogy.org.ua/index.php/PPS/issue/archive

This is an Open Access article distributed under the terms of the Creative Commons Attribution License, which permits unrestricted use, distribution, and reproduction in any medium, provided the original work is properly cited (http://creativecommons.org/licenses/by/4.0/deed.en).

Received: 07.11.2017

Accepted: 08.12.2017; Published: 30.04.2018 